\title{
Mir-21 Promotes Cardiac Fibrosis After Myocardial Infarction Via Targeting Smad7
}

\author{
Jinxia Yuan ${ }^{a}$ Hongtao Chen ${ }^{b}$ Dawei Ge ${ }^{b} \quad Y u X u^{a} \quad H a i h u a X u^{a} \quad Y^{a n g} Y_{a n g}{ }^{a}$ \\ Ming Gua Yuhe Zhou ${ }^{a}$ Jingdong Zhu ${ }^{a}$ Ting Ge ${ }^{a}$ Qun Chen ${ }^{a} \quad Y u e G^{a}$ \\ Yanqing Wang ${ }^{\mathrm{a}}$ Xiaowei $\mathrm{Li}^{\mathrm{a}}$ Yanfang Zhao ${ }^{\mathrm{a}}$ \\ aDepartment of Cardiology, Bayi Hospital Affiliated Nanjing University Of Chinese Medicine, \\ bDepartment of Orthopedics, the Affiliated Hospital of Nanjing Medical University, Nanjing, China
}

\section{Key Words}

Mir-21 • Cardiac fibrosis • Myocardial infarction • Smad7 • TGF- $\beta 1$

\begin{abstract}
Background/Aims: Cardiac fibrosis after myocardial infarction (MI) has been identified as an important factor in the deterioration of heart function. Previous studies have demonstrated that miR-21 plays an important role in various pathophysiological processes in the heart. However, the role of miR-21 in fibrosis regulation after MI remains unclear. Methods: To induce cardiac infarction, the left anterior descending coronary artery was permanently ligated of mice. First, we explored the expression of miR-21 in the infarcted zone in mice model of MI via RT-qPCR. Next, we examined the effects of TGF- $\beta 1$ on miR-21 expression in cardiac fibroblasts (CFs). Then, CFs were infected with miR-21 mimics or miR-21 inhibitors to investigate the effects of miR-21 on the process of CFs activation in vitro. Further, bioinformatics analysis and luciferase reporter assay were performed to identify and validate the target gene of miR-21. At last, in-vivo study was done to confirm MiR-21 regulated myocardial fibrosis after MI in mice. Results: MiR-21 was up-regulated in the infarcted zone after MI in vivo. TGF- $\beta 1$ treatment increased miR-21 expression in CFs. Overexpression of miR-21 promoted the effects of TGF$\beta 1$-induced activation of CFs, evidenced by increased expression of Col-1, $\alpha$-SMA and F-actin, whereas inhibition of miR-21 attenuated the process of fibrosis. Bioinformatics, Western blot analysis and luciferase reporter assay demonstrated that Smad7 is a direct target of miR-21. In addition, in-vivo study revealed that MiR-21 regulated myocardial fibrosis after MI in mice. Conclusion: These findings suggested that miR-21 has a critical role in CF activation and cardiac fibrosis after MI through via TGF- $\beta / S m a d 7$ signaling pathway. Thus, miR- 21 promises to be a potential therapy in treatment of cardiac fibrosis after MI.
\end{abstract}

J. Yuan, H. Chen and D. Ge contributed equally to this work.

Yanfang Zhao

KARGER
Department of Cardiology, Bayi Hospital Affiliated Nanjing, University Of Chinese Medicine. NO 34 Yanggongjing 34 Biao, Qinhuai Distinct, Nanjing City, Jiangsu Province (China) Tel. +86018205092248, E-Mail zhaoyanfang024@sina.com 


\section{Introduction}

Myocardial infarction (MI) remains the leading cause of death in the world, especially in Western countries $[1,2]$. In recent decades, major advances in prevention and treatment have led to dramatic decline in morbidity and mortality rates following MI [3, 4]. In spite of these advances in both the early management and longer-term treatment, MI was still a major cause of disability worldwide [5].

Multiple pathological changes appear in the heart after MI, among, cardiac fibrosis plays a vital role in regulating heart function and development of heart failure, and determining the size, shape and wall thickness of ventricles [6-8].. Accumulating evidence has demonstrated that excessive fibrosis would lead to ventricular dilation, infarct expansion, and heart failure [9-11]. Thus, effective interventions to inhibit cardiac fibrosis may have potential therapeutic effects on improving heart function and even reducing mortality risk [12-14].

MicroRNAs (miRNA) are short RNA sequences of 20-23 nucleotides. They act as negative regulators of gene expression by inhibiting mRNA translation or promoting mRNA degradation $[15,16]$. Recently, key roles of miRNAs in various pathophysiological processes, including cardiac fibrosis, were reported in a number of studies, indicating a new mode of regulation of cardiac diseases [17-20]. For instance, miR-21 was demonstrated to be an important regulator in fibroblasts proliferation and fibrosis [21], and miR-29, miR-30 and miR-133 have been found to inhibit collagen expression $[22,23]$. These miRNAs are known to interact with and modulate various components of fibrotic program. Among, miR-21 has been extensively studied because many of its targets are relevant to fibrosis and especially related to the modulation of TGF- $\beta 1$ signaling pathway, which has been demonstrated to play a central role in the onset and progression of fibrosis in multiple organs [24]. To date, miR-21 has been reported to be associated with fibrosis in experimental models of lung and kidney [25-27]. However, the role of miR-21 in cardiac fibrosis after MI remains unclear. The purpose of the present study was to elucidate whether miR-21 also plays a role in cardiac fibrosis and to investigate the potential mechanism in which miR-21 regulated this pathological process.

\section{Materials and Methods}

\section{Establishment of myocardial infarction in mice}

All animal protocols were approved by the Animal Ethic Committee of Nanjing University of Traditional Chinese Medicine. Male C57BL/6 mice (12 weeks; 25-30 g) were subjected to myocardial infarction ( $\mathrm{n}=9$ ) or sham surgery $(n=9)$ according to a previous report [28].In detail, after left thoracotomy and pericardiotomy, the left anterior descending coronary artery was permanently ligated with a 6-0 silk suture (MI group). Sham-operated animals underwent the same procedure but the coronary ligature was left untied (Sham group). Sections from different regions, including infarcted, remote and border zone, were prepared for further analysis.

\section{Echocardiography}

A VisualSonocs Vevo 2100 system (Visualsonics, Inc., Toronto, Canada) equipped with a 30-MHz RMV 707B scanhead was used for transthoracic echocardiographic analyses. Ventricular parameters, including systolic left ventricular volume, diastolic left ventricular volume, LV end systolic diameter and LV end diastolic diameter were measured. Moreover, heart weight/tibia length (HW/TL) and lung weight/tibia length (LW/TL) were also measured.

\section{Lentiviral expression constructs and transfer in vivo}

Lentiviral vectors including LV-miR-21-RNAi and LV-GFP were generated by Gene Chem Biology Company (Shanghai, China) and were used for mice transfection. As mentioned above, Male C57BL/6 mice (12 weeks; $25-30 \mathrm{~g})$ were subjected to myocardial infarction $(\mathrm{n}=18)$ or sham surgery $(\mathrm{n}=9)$. Fifteen minutes after surgery, lentiviral vectors containing $40 \mu \mathrm{L}$ of $1 \times 10^{9} \mathrm{TU} / \mathrm{mL}$ lentiviral particles were injected into myocardium of mice for MI group ( $\mathrm{n}=9$ for each group). 2 weeks after MI, mice were sacrificed and tissues were collected. 


\section{Cellular Physiology Cell Physiol Biochem 2017;42:2207-2219 \begin{tabular}{ll|l} 
and Biochemistry Published online: August 16, 2017 & $\begin{array}{l}\text { (c) } 2017 \text { The Author(s). Published by S. Karger AG, Basel } \\
\text { www.karger.com/cpb }\end{array}$
\end{tabular}}

Yuan et al.: MiR-21 Promotes Cardiac Fibrosis

\section{Histological Analysis}

Tissues used for histology were incubated in Krebs-Henselheit solution, fixed in 4\% paraformaldehyde, sectioned, and processed for Masson's Trichrome staining and immunohistochemical staining of $\alpha$-SMA. Protocols for Masson's Trichrome staining was according to a previous study [29]. For $\alpha$-SMA staining, sections from the hearts of Sham or MI mice were immunolabeled with anti- $\alpha$-SMA antibody (Abcam, Cambridge, MA, USA) to allow identification of the differentiation of myofibroblasts, as previously described [30].

\section{Cell culture}

Primary cardiac fibroblasts (CFs) were isolated from 1 to 3-day-old Sprague-Dawley rats purchased from the Experimental Animal Center of Nanjing University of Traditional Chinese Medicine as described previously [31]. CFs were cultured in DMEM containing $10 \%$ fetal bovine serum (FBS), $100 \mathrm{U} / \mathrm{ml}$ penicillin, and $100 \mathrm{ug} / \mathrm{ml}$ streptomycin at standard culture conditions $\left(37^{\circ} \mathrm{C}\right.$, with $\left.5 \% \mathrm{CO}\right)$. Cells were passaged at 70-80\% confluence, and cells at passage 2-3 were used in experiments.

\section{MiRNA mimic/inhibitor transfection}

MiR-21 mimic, miR-21 inhibitor, and a negative control (NC) were synthesized by Shanghai GenePharma (Shanghai, China). For transfection, CFs were seeded in 12 -well plates at a density of $5 \times 10^{4} / \mathrm{ml}$ and were transfected with $100 \mathrm{nM}$ of miR-21 mimic, miR-21 inhibitor or NC using Lipofectamine 3000 (Life technologies corporation, Gaithersburg, MD, USA) and then incubated for $6 \mathrm{~h}$. Following transfection, media were changed to 2\% FBS-DMEM without antibiotics. Smad7 siRNA (Cat \# 4392420) was obtained from Thermo Scientific (USA)) and it was used alone or in combination with miRNAs in the transient transfection.

\section{TGF- $\beta 1$ treatment}

CFs transfected with miR-21 mimic, miR21 inhibitor or NC were washed with phosphate-buffered saline (PBS) and then subjected to TGF- $\beta 1$ (Sigma, St. Louis, MO) with different concentrations $(50 \mathrm{ng} / \mathrm{ml}$, $10 \mathrm{ng} / \mathrm{ml}$ and $1 \mathrm{ng} / \mathrm{ml})$ and times $(24,48 \mathrm{~h}$ and $72 \mathrm{~h})$. The control groups were treated with PBS alone. After treatment, the cells were immediately washed three times with PBS for further analysis.

\section{Cell Viability Assay}

Cell viability was evaluated using a Cell Counting Kit-8 (CCK-8) Kit (Biosharp, Hefei, China) according to the manufacturer's instructions. CFs were plated in a 96-well plate in 6 replicates $\left(2 \times 10^{3} /\right.$ well, $\left.100 \mathrm{ul}\right)$. After plating for 24 hours, cells were subjected to various treatments. The CCK- 8 solution (10 ul) was added to each well, and the cells were incubated for 2 hours at $37^{\circ} \mathrm{C}$. After incubation, absorbance was measured at $450 \mathrm{~nm}$ with an automated microplate reader (Bio-Rad, Hercules, CA, USA).

\section{Cell Migration Assay}

Trasnswell assay was used to detect cell migration. The transwell chamber (BD, CA) was put into a 24well plate. The lower chamber was filled with 600ul DMEM with $10 \%$ FBS. $1 * 10^{5} \mathrm{CFs}$ in $100 \mathrm{ul}$ DMEM without FBS was seeded into the upper chamber. After incubation of 24 hours, fix cells with $4 \%$ paraformaldehyde and then use a cotton swab to remove cells on the upper side of chamber. Afterwards, cells on the lower side of chamber was stained with $0.1 \%$ crystal violet for 15 minutes and finally, cells crossed the chamber was counted under a microscope. Five random images ware selected for each chamber.

\section{Immunofluorescence Staining}

CFs were fixed with absolute ethyl alcohol for 15 minutes and then cells were treated with $0.3 \%$ Triton $\mathrm{X}-100$ for $30 \mathrm{~min}$ at room temperature. Afterwards, cells were blocked with $10 \%$ goat serum for 30 minutes at room temperature. After then, primary antibody diluted in FBS was added to cells for incubation at $4{ }^{\circ} \mathrm{C}$ overnight. In the second day, cells were incubated with DyLight 488nm Goat Anti-Mouse IgG (H+L) for 60 minutes at room temperature, and cell nuclei were stained with DAPI. Finally, cells were viewed under a confocal microscope. First antibody mouse anti-F-actin was obtained from abcam (USA). DyLight 488nm Goat Anti-Mouse IgG (H+L) was obtained from Amylight Scientific (China). 


\section{Cellular Physiology Cell Physiol Biochem 2017;42:2207-2219 \begin{tabular}{l|l|l} 
and Biochemistry Published onlıne: August 16, 2017 & $\begin{array}{l}\text { (c) } 2017 \text { The Author(s). Published by S. Karger AG, Basel } \\
\text { www.karger.com/cpb }\end{array}$
\end{tabular} \\ Yuan et al.: MiR-21 Promotes Cardiac Fibrosis}

\section{Quantitative RT-PCR}

To analyze mRNA and miRNA expression, total RNA samples from mice cardiac tissues or cultured CFs was extracted using TRIzol (Ambion, Austin, TX, USA) according to the manufacturer's protocols. For mRNA detection, total RNA (2.0 ug) was reverse transcribed using a PrimeScriptTM RT reagent Kit (TaKaRa) for cDNA synthesis, detailed protocols were previously described [32]. $\beta$-actin served as an internal control. For miRNA detection, we used a TaqMan MicroRNA Assay Kit (Applied Biosystems, USA) and U6 was used as an internal control. Gene expression was determined utilizing TaqMan reagents (Life Technologies, Gaithersburg, MD, USA) with fluorescence signals being normalized to 18s rRNA utilizing the ddCT method [33]. Primers were synthesized by Invitrogen (Shanghai, China) and shown as follow: (Col-1: forward: 5'-TGGCAAGAACGGAGATGAC-3'; reverse: 5'-TCCAAACCACTGAAACCTCTG-3'); (Fibronectin: forward: 5'- GCACATGTCTCGGGAATGGA-3'; reverse: 5'-ACACGTGCAGGAGCAAATGG-3'); (TGF- $\beta 1:$ forward: 5'-ACATTG ACTTCCGCAAGGAC-3'; reverse: 5'-TAGTACACGATGGGCAGTGG-3'); (Smad7: forward: 5'-GTGGCATACTGGGAGGAGAA-3'; reverse: 5'-GATGGAGAAACCAGGGAACA-3'); (miR21: forward: 5'-GCACCGTCAAGGCTGAGAAC-3; reverse: 5'- CAGCCCATCGACTGGTG-3') and (U6: forward: 5'-CTCGCTTCGGCAGCACA-3'; reverse: 5'- AACGCTTCACGAATTTGCGT-3').

\section{Western blot}

Denatured cell lysates $(40 \mu \mathrm{g})$ were run on $10 \%$ gels and transferred to PVDF membranes. Then, membranes were blocked with 5\% BSA in Tris-buffered saline containing $0.05 \%$ Tween (TBS-T) and incubated with primary antibodies in $0.5 \%$ TBS-T overnight. After washing, horseradish peroxidase (HRP)conjugated secondary antibodies were incubated with membranes for $1 \mathrm{~h}$ with TBST. Secondary antibodies were detected using ECL Plus (Amersham, Arlington Heights, IL, USA) and imaged with the GelDoc XRS (Bio-Rad, Hercules, CA, USA). The relative band densities were normalized to $\beta$-actin. Primary antibodies anti-Col-1 and anti- $\alpha$-SMA were obtained from Abcam (USA). Primary antibodies anti-Smad 7, anti-p-Smad 2 , anti-Smad 2, anti-p-Smad 3, anti-Smad 3 and anti- $\beta$-actin were obtained from CST technology (USA).

\section{MicroRNA target prediction}

The miRNA databases and target prediction tools miRBase (http:// microrna.sanger.ac.uk/), PicTar (http://pictar.mdc-berlin.de/), and TargetScan (http://www.targetscan.org/index.html) were used for identification of the potential targets of miR-21. We focused on targets predicted by at least two prediction databases and containing a miR-21-8mer seed match in the respective $3^{\prime} \mathrm{UTR}$ region.

\section{Luciferase reporter assay}

The Smad7 3'-UTR luciferase reporter vector was purchased from Genechem (Shanghai, China). Site-directed mutagenesis was performed using the QuickChange Lightning kit (Stratagene, La Jolla, CA, USA). To test suppression by miR-21, miR-21 of interest was co-transfected into HEK293T cells with the indicated wildtype or mutated 3'-UTR luciferase reporter and with Renilla luciferase (pRLTK Vector, Promega, Madison, WI, USA) as a transfection efficiency control. The luciferase signal was measured with Duo-Glo luciferase assay kit (Promega, Madison, WI, USA).

\section{Statistical analyses}

Data were expressed as the mean \pm SD. Statistical analyses were performed using SPSS 19.0 (IBM, Armonk, NY, USA). Differences among groups were tested by one-way ANOVA. Statistical analyses between two groups were evaluated based on the Student's two-tailed t-test. Differences between groups were evaluated using Fisher's least-significant difference post-test procedure. Differences were considered statistically significant when the p value was under 0.05 .

\section{Results}

MiR-21 expression is up-regulated after MI

After MIsurgery, the physiological parameters of mice were assessed by echocardiography. Comparing to sham group, MI group showed increased LV volume, LVEDD, LVESD, HW/TL and LW/TL (Fig. 1A). Meantime, to investigate the effects of MI on miR-21 expression, we 


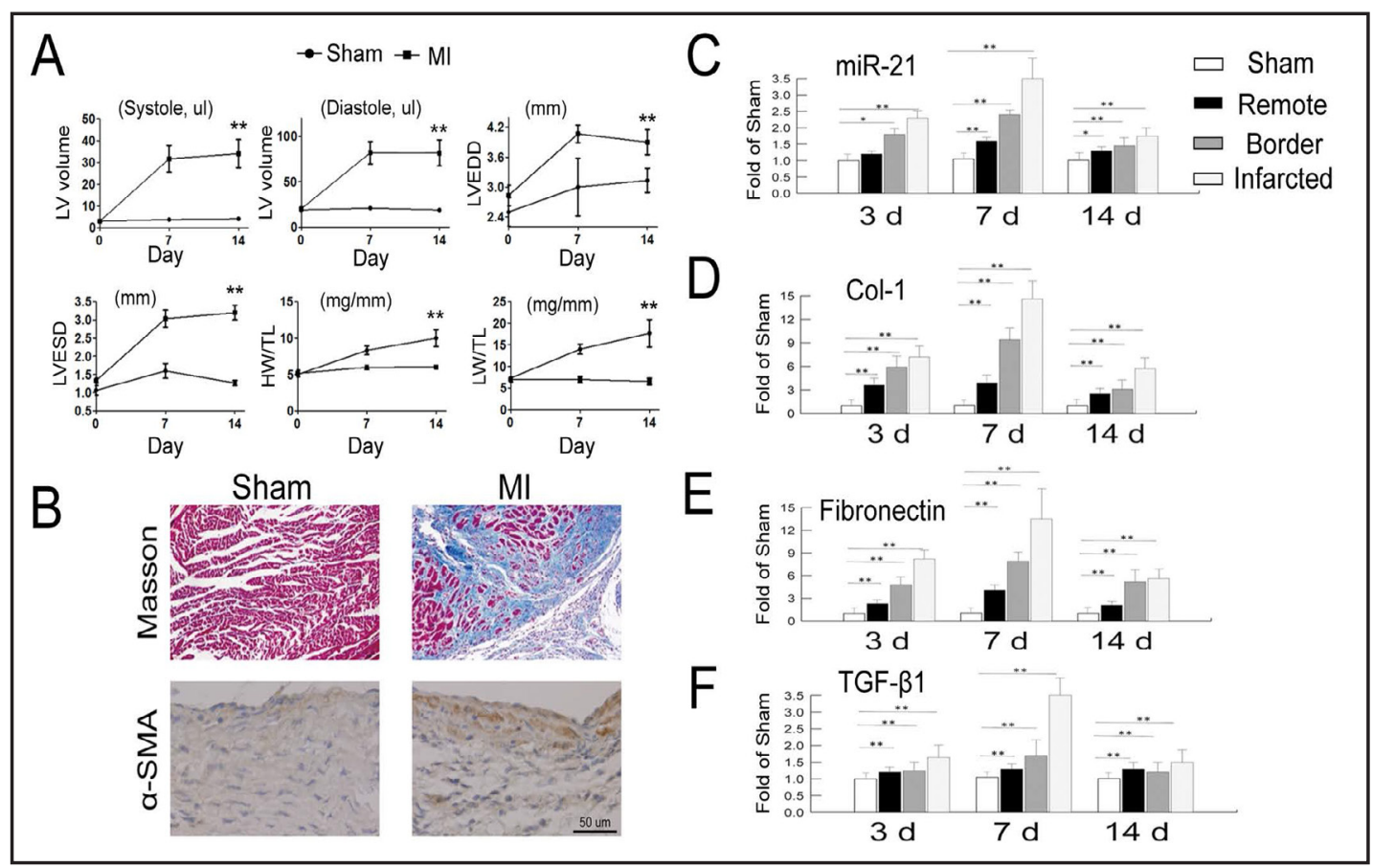

Fig. 1. MiR-21 expression is up-regulated in the hearts of MI mice: A: Increased LV volume, LV diameter, heart weight/tibia length and lung weight/tibia length of MI mice than sham mice at various time-points; B: Masson staining and IHC staining of $\alpha$-SMA of the heart sections from Sham and MI mice 14 days after LAD ligation of the heart; C: miR-21 expression of heart tissues from different regions (Infarcted zone, Border zone, Remote zone and SHAM) at 3d, $7 \mathrm{~d}$ and $14 \mathrm{~d}$; D-F: mRNA expression of Col-1, Fibronectin and TGF- $\beta 1$ at various time-points and different regions. ${ }^{*} \mathrm{P}<0.05,{ }^{* *} \mathrm{P}<0.01$ ( $\mathrm{n}=9$ for each group).

first monitored cardiac fibrosis in the heart at different time points after MI. As we expected, Masson's Trichrome staining and IHC of $\alpha$-SMA demonstrated significant fibrosis in the infarcted zone after MI (Fig. 1B). Then we measured expression of the miR-21 at various time-points (3d, 7d and 14d) and different regions (I, BZ, R and SHAM) in mice models of MI. Results showed that miR-21 was significantly upregulated in the heart after MI, especially in the infarcted zone of the heart (Fig. $1 \mathrm{C}$ ). To further delineate the association of expression change of miR-21 with cardiac fibrosis, we additionally explored the expression of Col-1 and fibronectin, which are all key fibrotic markers [34, 35]. As expected, RT-PCR showed that expression level of both COL1 and fibronectin significantly increased at $3 \mathrm{~d}$ and peaked at $7 \mathrm{~d}$ after MI and subsequently gradually decreased, which was consistent with expression change of miR-21 (Fig. $1 \mathrm{D}$ and E). As previous evidence suggested, TGF- $\beta 1$ plays a central role in the onset and progression of cardiac fibrosis after MI, we also measured mRNA levels of TGF- $\beta 1$. Results revealed a significant increase of TGF- $\beta 1$ mRNA at $7 d$ in the infarcted zone (Fig. 1 F).

Fig. 2. TGF- $\beta 1$ up-regulated expression of miR-21 in CFs: CFs were treated with TGF- $\beta 1$ at indicated concentrations $(1,10,50 \mathrm{ng} / \mathrm{ml})$ for the indicated time. miR-21 cluster levels were determined by qRTPCR ( $\mathrm{n}=3) .{ }^{*} \mathrm{P}<0.05,{ }^{* *} \mathrm{P}<0.01$.

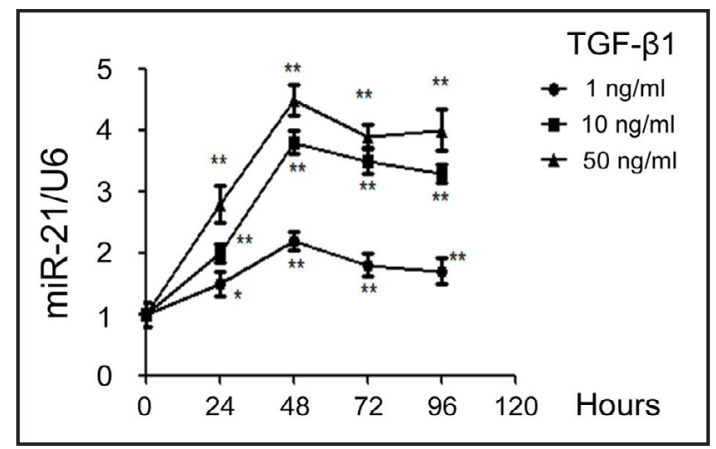




\section{Cellular Physiology

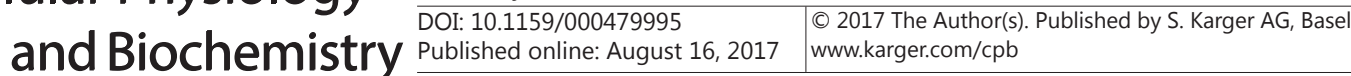 \\ Yuan et al.: MiR-21 Promotes Cardiac Fibrosis}

Fig. 3. The influence of miR-21 on proliferation and migration of CFs: A: Cell proliferation of CFs transfected with miR-21 mimics, miR-21 inhibitors or NC detected by CCK-8 assay; B: A transwell migration assay was used to detect the role of miR-21 in CF migration. Representative images of CFs transfected with miR-21 mimics, miR-21 inhibitors or NC migrated towards $1 \%$ serum media. Quantitative analyses demonstrated the difference in CF migration. NS, none significant difference, ${ }^{* *} \mathrm{P}<0.01(\mathrm{n}=3)$.

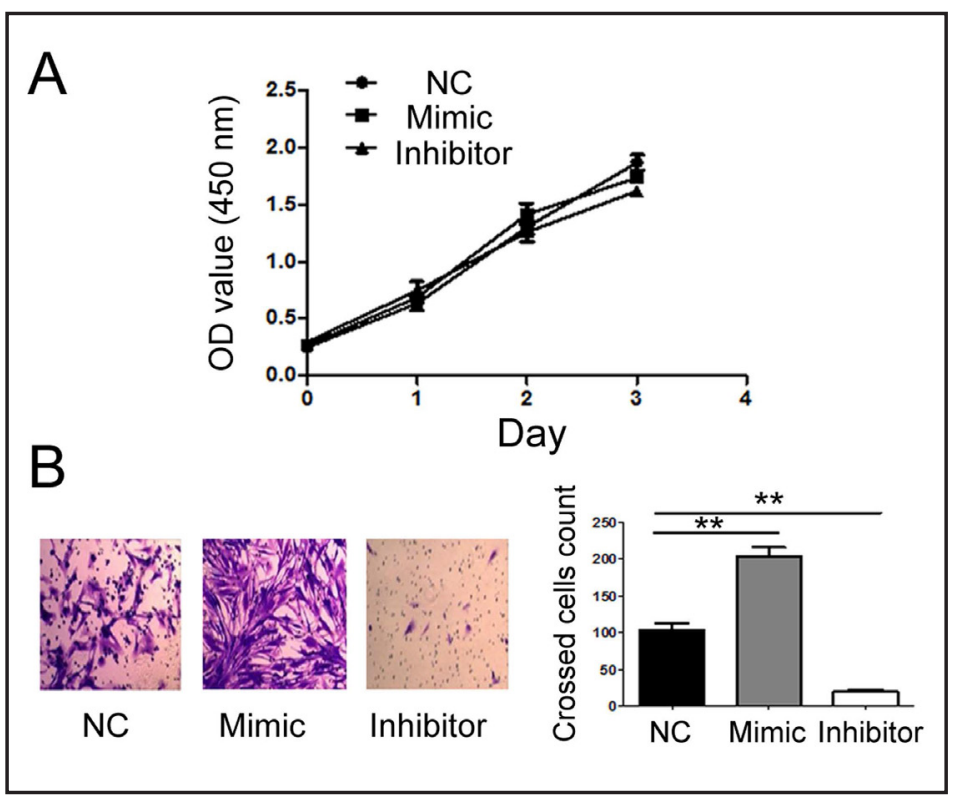

\section{Effect of TGF- $\beta 1$ on miR-21 expression in vitro}

To verify the role of TGF- $\beta 1$ on miR- 21 expression, CFs were treated with different concentrations of TGF- $\beta 1$ ( $50 \mathrm{ng} / \mathrm{ml}, 10 \mathrm{ng} / \mathrm{ml}$ and $1 \mathrm{ng} / \mathrm{ml}$ ) for $24 \mathrm{~h}, 48 \mathrm{~h}, 72 \mathrm{~h}$ and $96 \mathrm{~h}$. Nonetreated cells were served as control. As shown in Fig. 2, TGF- $\beta 1$ increased miR-21 in a dosedependent manner. These results demonstrated the effects of TGF- $\beta 1$ on miR- 21 expression.

\section{The influence of miR-21 on proliferation and migration of CFS}

To figure out the mechanism in which miR-21 exerts its biological effects in the process of cardiac fibrosis, we first performed CCK8 assay to evaluate the effects of miR-21 on the proliferation of CFs. Results showed that cell vitality of CFs infected with miR-21 mimics or miR-21 inhibitors was not significantly different from that in cells infected with NC, indicating that inhibition or overexpression of miR-21 had no significant effect on proliferation of CFs (Fig. 3A). Meantime, we measured the effects of miR-21 on the migration of CFs. As showed in Fig. 3B, as compared to negative control group, miR-21 mimic promoted cell migration of CFs, while miR-21 inhibitor inhibited cell migration of CFs.

\section{MiR-21 promoted activation of CFS}

To further explore the role of miR-21 in the process of TGF- $\beta 1$-induced fibrosis in CFs, cells were transfected with miR-21 mimics, miR-21 inhibitors or NC before treating with TGF- $\beta 1(10 \mathrm{ng} / \mathrm{ml})$ or PBS. We found that TGF- $\beta 1$ treatment significantly increased expression of Col- 1 and $\alpha$-SMA both in mRNA and protein levels (Fig. 4A and B). Interestingly, overexpression of miR-21 with miR-21 precursor mimics markedly promoted TGF- $\beta 1$ induced increase of Col- 1 and $\alpha$-SMA in both mRNA and protein levels. In addition, inhibition of miR-21 with miR-21 inhibitors partly reversed the effects of TGF- $\beta 1$ on upregulation of the above markers (Fig. 4C). Meantime, we also detected the expression of F-actin, results showed that overexpression of miR-21 with miR-21 precursor mimics markedly promoted the expression of F-actin, while miR-21 inhibitors reversed the effects of upregulation of F-actin (Fig. 4D). These results revealed that miR-21 can promote activation of CFs.

\section{Smad7 is a direct target of miR-21}

To study the further molecular mechanism by which miR-21 regulates the process of fibrosis in CFs, we used databases of miRanda, TargetScan and PicTar to search for potential target genes that have an established function in regulating fibrosis. Among the candidate fibrosis-associated target genes, we found that Smad7 has a miR-21 binding site (8-nt) in 


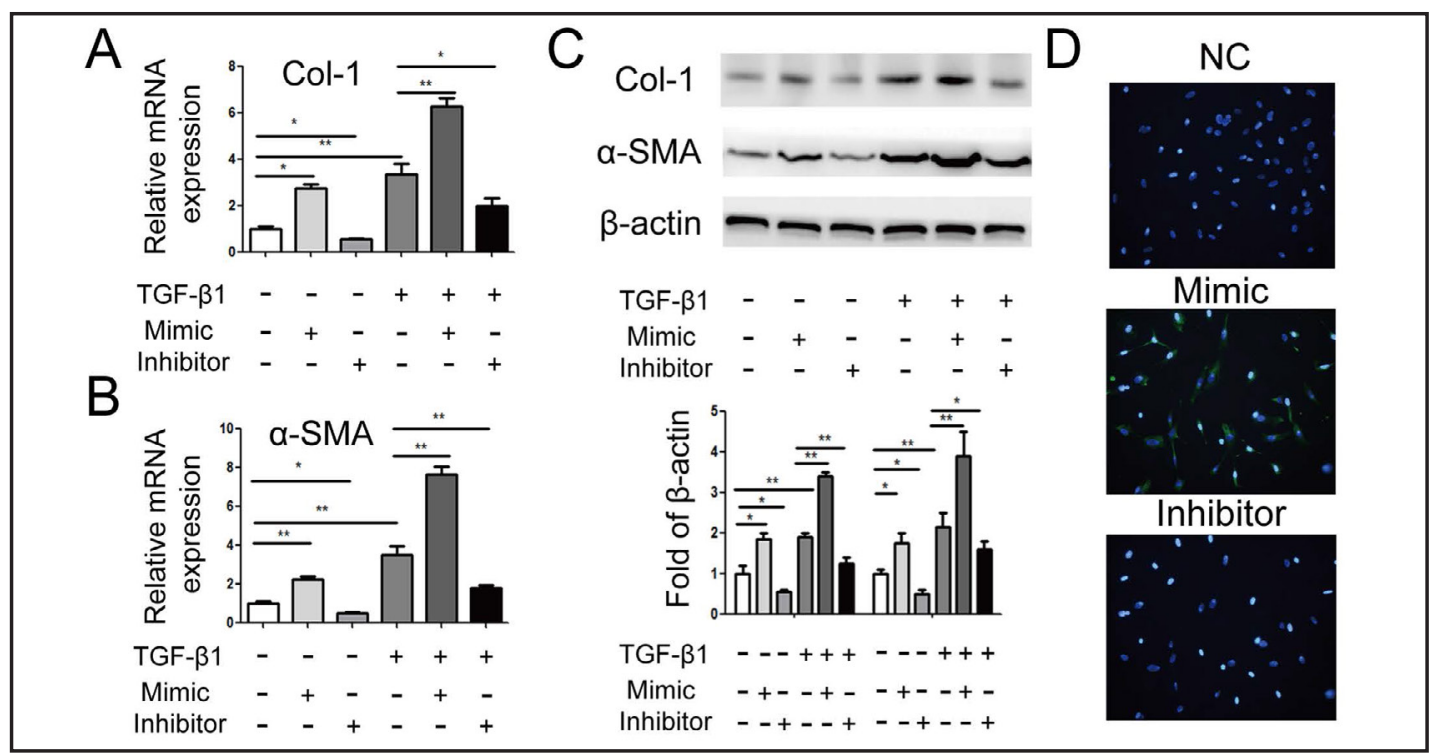

Fig. 4. Over expression of miR-21 enhanced activation of CFs: A-B: mRNA expressions of Col-1 and $\alpha$-SMA in CFs infected with miR-21 mimics, miR-21 inhibitors or NC were measured by qRT-PCR; C: protein expressions of Col-1 and $\alpha$-SMA in CFs infected with miR-21 mimics, miR-21 inhibitors or NC were evaluated by Western blot; D: F-actin expression of CFs infected with miR-21 mimics, miR-21 inhibitors or NC was detected by immunofluorescence under $\times 400$ magnification. ${ }^{*} \mathrm{P}<0.05,{ }^{* *} \mathrm{P}<0.01(\mathrm{n}=3)$.

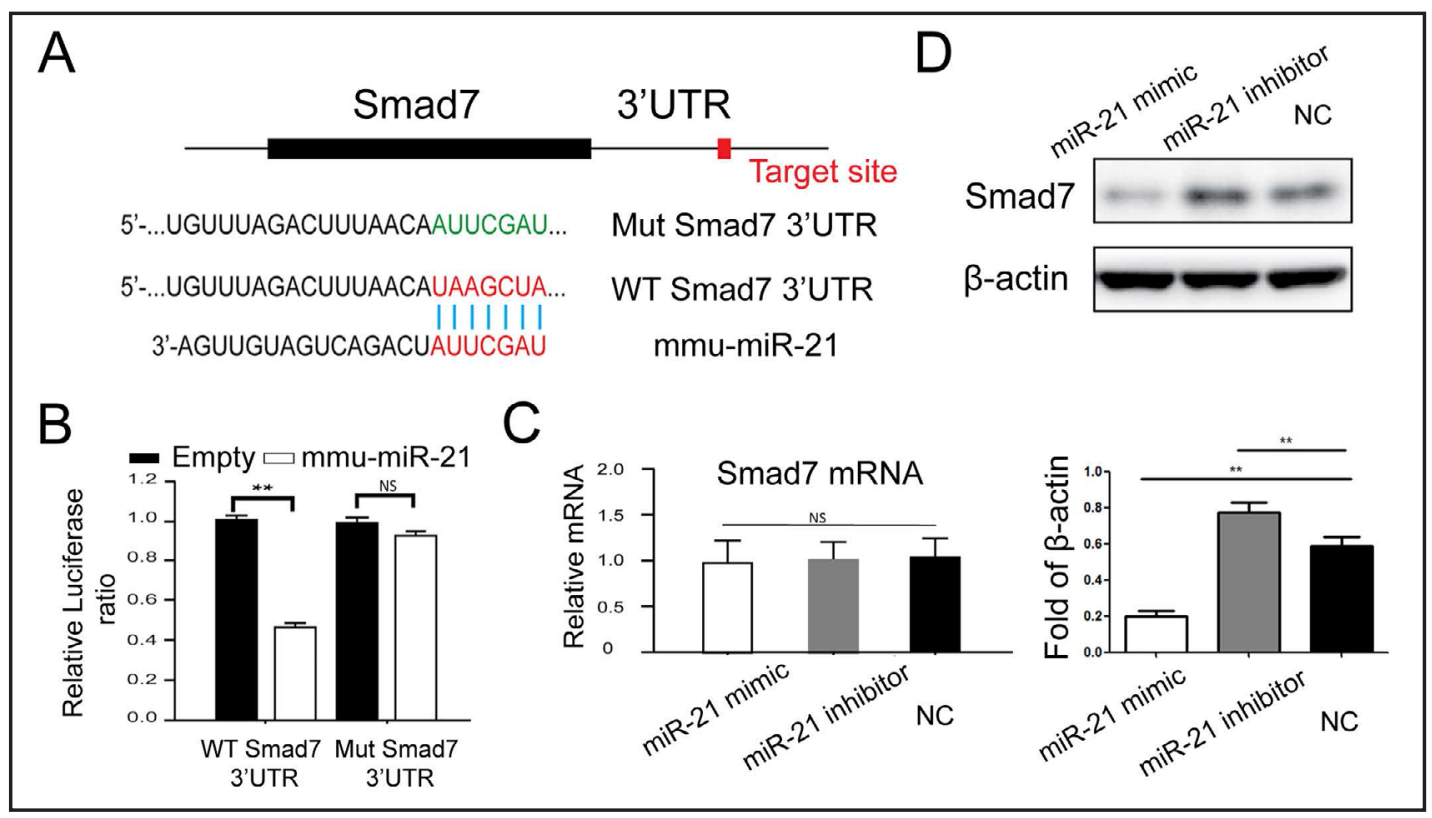

Fig. 5. Smad7 was a direct target of miR-21: A: Schematic diagram illustrating the design of luciferase reporters with the wild-type Smad7 3'UTR (WT Smad7 3'UTR) or the site-directed mutant Smad7 3'UTR (Mut Smad7 3'UTR); B: Luciferase reporter assays in HEK293T cells, with co-transfection of WT or Mut Smad7 3'-UTR and miR-21 as indicated; C: mRNA of Smad7 in CFs infected with miR-21 mimics, miR21 inhibitors or NC were detected by RT-qPCR ; D: Western blot analysis for Smad7 protein; bar graphs represent quantifications of Western blot results relative to $\beta$-actin. NS, none significant difference, ${ }^{*} \mathrm{P}<0.05$, $* * \mathrm{P}<0.01(\mathrm{n}=3)$.

its 3'UTR (Fig. 5A). To examine whether miR-21 could suppress expression of Smad7 via binding to its 3'-UTR, we co-transfected a luciferase reporter vector containing the Smad7 3'- 


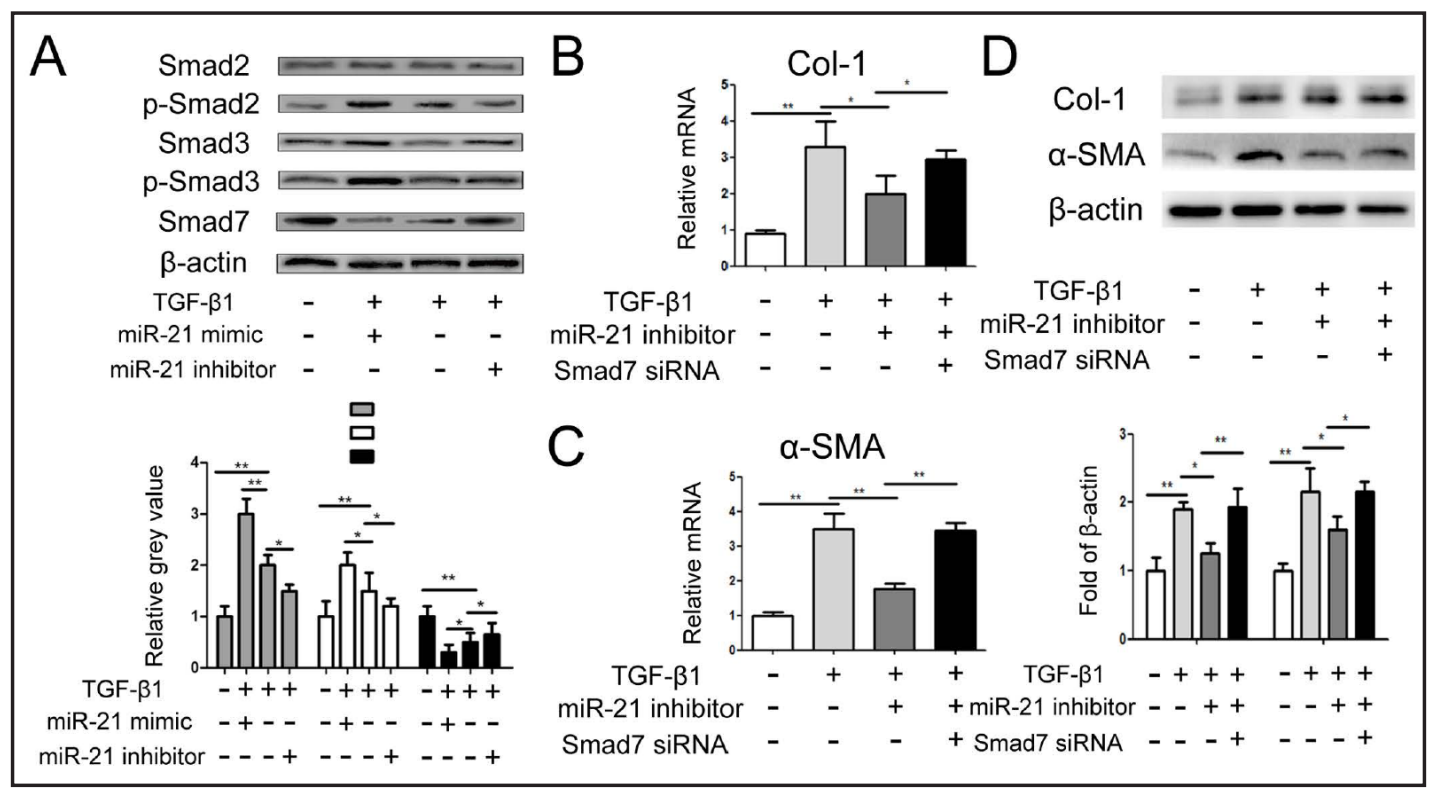

Fig. 6. MiR-21 inhibits TGF- $\beta / \operatorname{Smad} 2 / 3$ signaling: A: Western blot analysis for Smad2, p-Smad2, Smad3, p-Smad3 and Smad7; B-D: knockdown of Smad7 can rescue the CF activation repressed by miR-21 inhibitor; B and C: mRNA expressions of Col-1 and $\alpha$-SMA in CFs transfected with miR-21 inhibitors with or without Smad7 siRNA measured by qRT-PCR; C: protein expressions of Col-1 and $\alpha$-SMA in CFs transfected with miR21 inhibitors with or without Smad7 siRNA measured by Western blot. ${ }^{*} \mathrm{P}<0.05$, ${ }^{*} \mathrm{P}<0.01(\mathrm{n}=3)$.

UTR along with a vector expressing miR-21 in HEK293T cells. Initial experiments revealed that Smad7 3'-UTR expression is repressed by miR-21. To assess whether this regulation is indeed due to miR-21 recognizing its predicted binding site in Smad7 rather than other nonspecific actions, we then mutated the seed region in Smad7 for miR-21 binding (Fig. 5B) and performed the luciferase assays as above. Results revealed that the wild-type (WT) Smad7 shows significant repression by miR-21, however, the mutant Smad7 does not (Fig. 5B). Then we performed qRT-PCR and Western Blot to explore the effects of miR-21 on mRNA and protein levels of Smad7. Gene expression analysis revealed no significant changes in Smad7 mRNA levels after infecting with miR-21 mimics or inhibitors (Fig. 5C), while Western blot analysis revealed significant reduced Smad7 protein levels when miR-21 was overexpressed in CFs (Fig. 5D). All the results demonstrated that Smad7 is a direct target of miR-21.

\section{MiR-21 promoted fibrotic process via suppression of Smad7 signaling pathway}

To figure out whether miR-21 promoted CFs fibrosis through suppressing Smad7 signaling, we further explored phosphorylation levels of Smad2 and Smad3, which have been demonstrated to be negatively regulated by Smad7 and play a central role in activation of fibroblasts [36]. As shown in Fig. 6A, Smad7 was inhibited after treatment with TGF- $\beta 1$ $(10 \mathrm{ng} / \mathrm{ml})$ however, phosphorylation levels of Smad 2 and Smad 3 were elevated. In addition, overexpression of miR-21 using miR-21 mimics significantly promoted the effects of TGF- $\beta 1$ induced decrease of Smad7, thus further increased phosphorylation of Smad2 and Smad3. Inhibition of miR-21 exerted the inverse effects. To further confirm the effect of Smad7 in miR21 mediated CFs fibrosis, a Smad7 siRNA was used for transfection with miR-21 inhibitor. As shown in Fig. 6B and 6C, miR-21 inhibitor decreased mRNA expression of TGF- $\beta 1$ triggered Col-1 and $\alpha$-SMA expression. Meantime, the protein level of Col-1 and $\alpha$-SMA had the same trend of mRNA changes (Fig. 6D).

MiR-21 regulates myocardial fibrosis 2 weeks after MI

Next, we performed in-vivo experiment to confirm miR-21's effect in MI. After MI surgery, we injected LV-GFP or LV-miR-21-RNAi intramyocardially of MI mice $(n=9$ per 


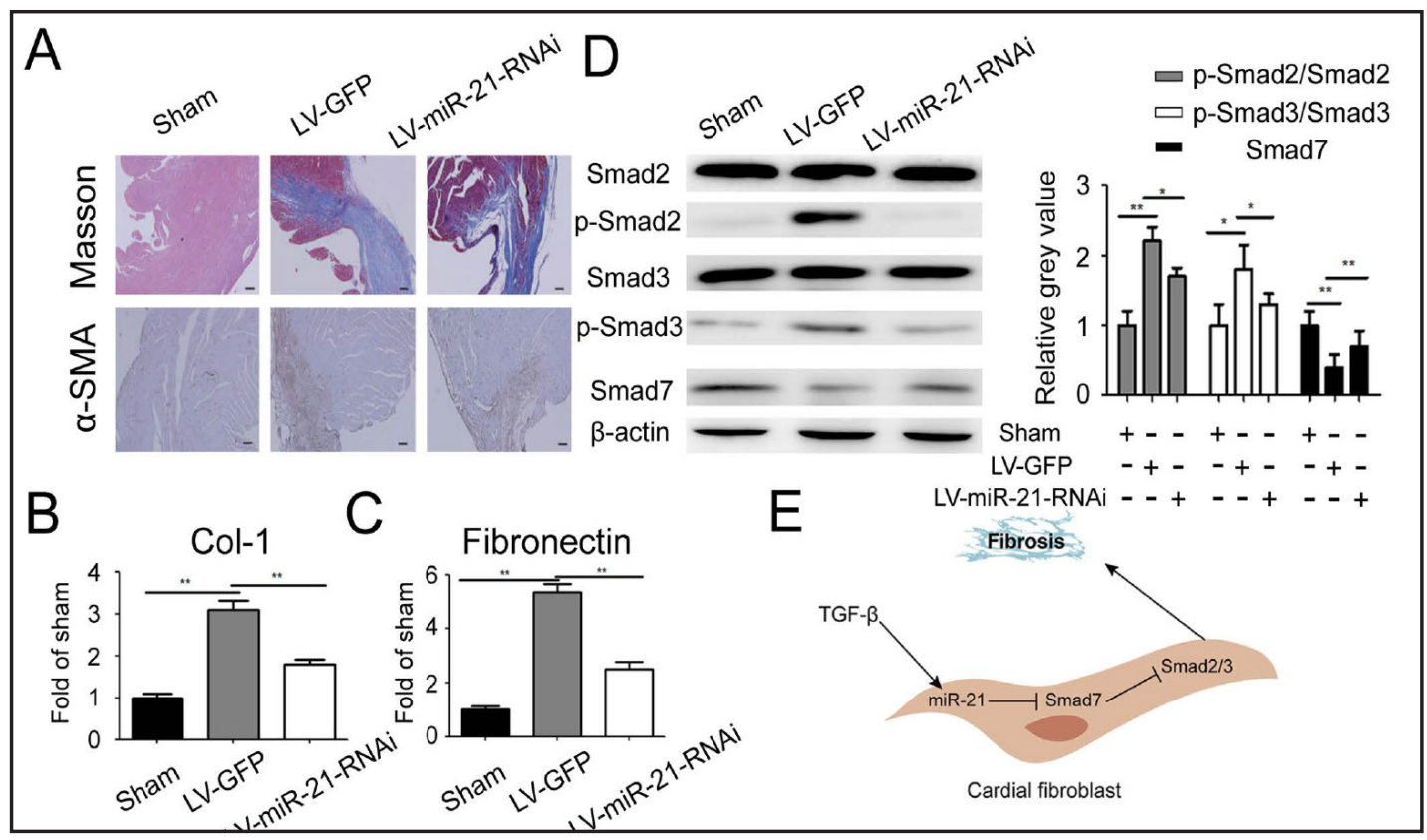

Fig. 7. MiR-21 regulates myocardial fibrosis 2 weeks after MI: Mice receiving control lentiviral vector-GFP (LV-GFP) or lentiviral vector-miR-21-RNAi (LV- miR-21-RNAi) were killed 2 weeks after MI. A: Masson staining and IHC staining of $\alpha$-SMA of the border zone of infracted heart from sham and MI mice; B and C: mRNA expression of Col-1 and Fibronectin in the border zone; D: protein expressions of Smad2, p-Smad2, Smad3, p-Smad3 and Smad7 measured by Western blot. ${ }^{*} \mathrm{P}<0.05,{ }^{*} \mathrm{P}<0.01(\mathrm{n}=9)$. E: A model for the role of miR-21 in cardiac fibrosis: TGF- $\beta$ triggers the up-regulation of miR-21 in cardiac fibroblasts and consequently inhibits expression of Smad7. Down-regulation of Smad7 increases phosphorylation levels of Smad2/3, consequently promotes fibroblasts activation and cardiac fibrosis.

group). 2 weeks after MI surgery, mice were sacrificed. Masson staining showed LV-miR21-RNAi could reverse the fibrosis of MI. Meantime, $\alpha$-SMA expression was decreased in LV-miR-21-RNAi group than LV-GFP group (Fig. 7A). mRNA expression of Col-1 and $\alpha$-SMA were decreased in LV-miR-21-RNAi group than LV-GFP group (Fig. 7B and C). In addition, in LV-GFP group, Smad7 was inhibited, and phosphorylation levels of Smad2 and Smad3 were elevated than sham group, while LV- miR-21-RNAi could reverse the protein expression (Fig. 7D). All these results suggested the effects of miR-21 on promoting cardiac fibrosis was achieved through inhibiting Smad7 and thereby activating TGF- $\beta / S m a d 2 / 3$ signaling pathway (Fig. 7E).

\section{Discussion}

Cardiac fibrosis, which was an important part of cardiac remodeling, resulted in stiffening of the ventricular walls and diminished contractility and abnormalities in cardiac conductance, was a common consequence of numerous forms of heart diseases, including pathological hypertrophy, volume overload, and MI [37, 38].

In the past decade, numerous evidence has demonstrated the role of microRNAs in various pathophysiological processes, including cardiac fibrosis [17-20]. Among these fibrosis-related microRNAs, miR-21 was previously reported to play an important role in regulation of fibrosis in multiple tissues, such as kidney, liver and lung etc [25-27]. In the present study, we established mice models of cardiac fibrosis after MI and examined miR-21 expression at different time points and different cardiac zones.

First, we found that miR-21 was up-regulated after MI, and change in miR-21 expression was the most remarkable in the infarcted zone, In addition, change of miR-21 level was 


\section{Cellular Physiology Cell Physiol Biochem 2017;42:2207-2219 \\ and Biochemistry Published online: August 16, 2017 \begin{tabular}{l|l} 
DOI: 10.1159/000479995 2017 The Author(s). Published by S. Karger AG, Basel \\
www.karger.com/cpb
\end{tabular} \\ Yuan et al.: MiR-21 Promotes Cardiac Fibrosis}

consistent with levels of Col-1 and fibronectin, which were key markers in the development of fibrosis (Fig. 1). These results indicated that miR-21 level was associated with the extent of fibrosis. TGF- $\beta 1$ was known to play a central role in the onset and progression of fibrosis $[39,40]$. The fibrotic effects of TGF- $\beta 1$ were primarily mediated by the well characterized Smad2/3-dependent pathway $[41,42]$. Given this, we examined the correlation of miR-21 change with TGF- $\beta 1$. As expected, change trend of TGF- $\beta 1$ mRNA was similar to miR-21 (Fig. 2).

Second, CCK-8 assay showed that miR-21 had no effect of proliferation of CFs, but it could promote the serum-mediated migration of CFs (Fig. 3 ). Then, we employed TGF- $\beta 1$ to induce fibrosis in vitro and explored the effects of TGF- $\beta 1$ on miR-21 expression in CFs. Results revealed significant up-regulation of miR-21 after treatment with TGF- $\beta 1$ at a dosedependent manner. Then we examined whether overexpression or inhibition of miR-21 had effects on fibrosis in presence of TGF- $\beta 1$. Results showed that overexpression of miR-21 using miR-21 mimics in CFs enhanced the effects of TGF- $\beta 1$ on up-regulating expression of $\alpha$-SMA, Col-1, fibronectin and F-actin (the fibrotic signals), while inhibition of miR-21 partially reversed the effects of TGF- $\beta 1$ (Fig. 4). These results suggested that the effects of miR-21 in promoting the process of cardiac fibrosis was not dependent on TGF- $\beta 1$.

Lastly, we employed several databases for miR-21 target prediction. Among the candidates, Smad7 was previously reported to be a target of miR-21 in regulation of renal fibrosis [43]. Previous evidence showed that Smad7 is an attenuator in TGF- $\beta /$ Smad signaling, which has been demonstrated to one of the classical pathways involved in the process of fibroblasts activation and thus plays a key role in the onset and development of fibrosis [44-46]. TGF- $\beta$ binds to and activates its specific receptors (TGF- $\beta$ RI, TGF- $\beta$ RII) and consequently stimulates the phosphorylation of Smad2 and Smad3. Phosphorylated Smad2 and Smad3 form complexes with Smad4 [47, 48]. Then the complex translocate from cytoplasm into nucleus to regulate the transcription of the target genes, including Smad7, which negatively regulates Smad 2 and Smad3 activation and inhibits fibrosis [49, 50]. Given all above, we chose Smad7 as the candidate target for further validation.

To verify this hypothesis, we employed Luciferase reporter assay and results showed that Smad7 3'-UTR expression was inhibited by miR-21, indicating Smad7 was a direct target of miR-21 (Fig. 5). Next we measured protein levels of Smad7, Smad2 and Smad3 in the infarcted zone of mice MI models in vivo and in CFs treated with miR-21 mimics or inhibitors in vitro. We have noticed that protein level of Smad7 decreased after MI, while Smad2 and Smad3 increased. The change trend of Smad7 was negatively correlated with miR-21. Furthermore, in vitro, overexpression of miR-21 in CFs with or without pretreatment of TGF- $\beta 1$ attenuated expression of Smad7, however increased Smad2 and Smad3 (Fig. 6). Meanwhile, we performed in-vivo experiment to confirm miR-21 effect in MI. Results showed that inhibiting miR-21 could reverse the fibrosis of MI via Smad7 signaling pathway (Fig. 7). Results both in vivo and in vitro indicated that miR-21 exhibited its effects via targeting Smad7.

Here we proposed a model to explain the role of miR-21 in the process of fibrosis, which was outlined in Fig. 7E. In general, TGF- $\beta 1$ up-regulated miR-21 expression, thus attenuated protein expression of its target Smad7. Down-regulation of Smad7 enhanced phosphorylation of Smad 2 and Smad3 and subsequently promoted CFs activation and cardiac fibrosis. This is the first evidence to suggest a novel role for miR-21 in regulating cardiac fibrosis after MI.

Limitations still existed in our study. Although our results suggested a key role for miR21 in the regulation of cardiac fibrosis, it is important to note that there was not a direct oneto-one stoichiometric relationship between the levels of miR-21 and Smad7. Additionally, as we all know, microRNA has a number of target genes, our study does not exclude that miR-21 contribute to development of cardiac fibrosis also via targeting other genes. We only verified that Smad7 plays a role in this process. Furthermore investigations are needed to elucidate the underlying mechanism of miR-21 in affecting the onset and development of cardiac fibrosis after MI. 


\section{Cellular Physiology Cell Physiol Biochem 2017;42:2207-2219

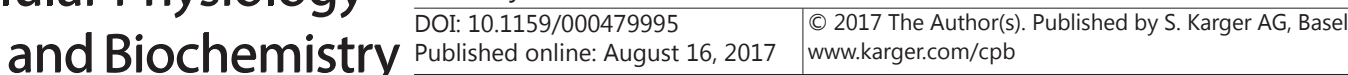 \\ Yuan et al.: MiR-21 Promotes Cardiac Fibrosis}

\section{Conclusion}

In summary, the present study analyzed expression and correlation of miR-21 with cardiac fibrosis in mice models of MI in vivo and delineated the role of miR-21 in CFs in vitro. Both in-vivo and in-vitro results demonstrated that miR-21 promoted cardiac fibrosis via targeting Smad7. Our findings may provide new insights into the mechanisms underlying cardiac fibrosis and provide novel potential therapeutic targets for cardiac fibrosis after MI.

\section{Acknowledgements}

This study was supported by Military Medical Science and Technology Innovation Project 2015 (NO: 15MS062).

\section{Disclosure Statement}

The authors declare no financial or other conflicts of interest.

\section{References}

1 Rosamond WD, Chambless LE, Folsom AR, Cooper LS, Conwill DE, Clegg L, Wang CH, Heiss G: Trends in the incidence of myocardial infarction and in mortality due to coronary heart disease, 1987 to $1994 \mathrm{~N}$ Engl J Med 1998;339:861-867.

-2 Barchielli A, Profili F, Balzi D, Francesconi P, Zuppiroli A, Cipriani F: [Trends in occurrence, treatment, and outcomes of acute myocardial infarction in Tuscany Region (Central Italy), 1997-2010]. Epidemiol Prev 2015;39:167-175.

-3 Coady SA, Johnson NJ, Hakes JK, Sorlie PD: Individual education, area income, and mortality and recurrence of myocardial infarction in a Medicare cohort: The National Longitudinal Mortality Study. BMC Public Health 2014;14:705.

4 Gjesing A, Gislason GH, Kober L, Gustav SJ, Christensen SB, Gustafsson F, Olsen AM, Torp-Pedersen C, Andersson C: Nationwide trends in development of heart failure and mortality after first-time myocardial infarction 1997-2010: A Danish cohort study. Eur J Intern Med 2014;25:731-738.

5 Paiva L, Providencia R, Barra S, Dinis P, Faustino AC, Goncalves L: Universal definition of myocardial infarction: Clinical insights. Cardiology 2015;131:13-21.

6 Raiskina ME: [Dynamics of the pathological changes in the heart during the acute stage of experimental myocardial infarct]. Kardiologiia 1967;7:3-13.

-7 Uusimaa P, Risteli J, Niemela M, Lumme J, Ikaheimo M, Jounela A, Peuhkurinen K: Collagen scar formation after acute myocardial infarction: Relationships to infarct size, left ventricular function, and coronary artery patency. Circulation 1997;96:2565-2572.

$>8$ Prabhu SD, Frangogiannis NG: The biological basis for cardiac repair after myocardial infarction: From inflammation to fibrosis. Circ Res 2016;119:91-112.

-9 Warren SE, Royal HD, Markis JE, Grossman W, McKay RG: Time course of left ventricular dilation after myocardial infarction: Influence of infarct-related artery and success of coronary thrombolysis. J Am Coll Cardiol 1988;11:12-19.

-10 Dambrink JH, Beukema WP, Van Gilst WH, Peels KH, Lie KI, Kingma JH: Left ventricular dilatation and highgrade ventricular arrhythmias in the first year after myocardial infarction. CATS Investigators. Captopril and Thrombolysis Study. J Card Fail 1994;1:3-11.

11 Foster CR, Daniel LL, Daniels CR, Dalal S, Singh M, Singh K: Deficiency of ataxia telangiectasia mutated kinase modulates cardiac remodeling following myocardial infarction: Involvement in fibrosis and apoptosis. Plos One 2013;8:e83513. 


\section{Cellular Physiology Cell Physiol Biochem 2017;42:2207-2219 \begin{tabular}{l|l|l} 
and Biochemistry Published online: August 16, 2017 & $\begin{array}{l}\text { (c) } 2017 \text { The Author(s). Published by S. Karger AG, Basel } \\
\text { www.karger.com/cpb }\end{array}$
\end{tabular} \\ Yuan et al.: MiR-21 Promotes Cardiac Fibrosis}

12 Xu L, Yates CC, Lockyer P, Xie L, Bevilacqua A, He J, Lander C, Patterson C, Willis M: MMI-0100 inhibits cardiac fibrosis in myocardial infarction by direct actions on cardiomyocytes and fibroblasts via MK2 inhibition. J Mol Cell Cardiol 2014;77:86-101.

13 Kanemitsu H, Takai S, Tsuneyoshi H, Nishina T, Yoshikawa K, Miyazaki M, Ikeda T, Komeda M: Chymase inhibition prevents cardiac fibrosis and dysfunction after myocardial infarction in rats. Hypertens Res 2006;29:57-64.

14 Fan GP, Wang W, Zhao H, Cai L, Zhang PD, Yang ZH, Zhang J, Wang X: Pharmacological inhibition of focal adhesion kinase attenuates cardiac fibrosis in mice cardiac fibroblast and Post-Myocardial-Infarction models. Cell Physiol Biochem 2015;37:515-526.

15 Shukla GC, Singh J, Barik S: MicroRNAs: Processing, maturation, target recognition and regulatory functions. Mol Cell Pharmacol 2011;3:83-92.

16 Bartel DP: MicroRNAs: Target recognition and regulatory functions. Cell 2009;136:215-233.

17 Silvestri P, Di Russo C, Rigattieri S, Fedele S, Todaro D, Ferraiuolo G, Altamura G, Loschiavo P: MicroRNAs and ischemic heart disease: Towards a better comprehension of pathogenesis, new diagnostic tools and new therapeutic targets. Recent Pat Cardiovasc Drug Discov 2009;4:109-118.

18 Lima JJ, Batty JA, Sinclair H, Kunadian V: MicroRNAs in ischemic heart disease: From pathophysiology to potential clinical applications. Cardiol Rev 2016

19 Hong Y, Cao H, Wang Q Ye J, Sui L, Feng J, Cai X, Song H, Zhang X, Chen X. MiR-22 may Suppress Fibrogenesis by Targeting TGFßR I in Cardiac Fibroblasts. Cell Physiol Biochem. 2016;40(6):1345-1353.

20 Deng P, Chen L, Liu Z, Ye P, Wang S, Wu J, Yao Y, Sun Y, Huang X, Ren L, Zhang A, Wang K, Wu C, Yue Z, Xu X, Chen M. MicroRNA-150 Inhibits the Activation of Cardiac Fibroblasts by Regulating c-Myb. Cell Physiol Biochem. 2016;38(6):2103-22.

-21 Thum T, Gross C, Fiedler J, Fischer T, Kissler S, Bussen M, Galuppo P, Just S, Rottbauer W, Frantz S, Castoldi M, Soutschek J, Koteliansky V, Rosenwald A, Basson MA, Licht JD, Pena JT, Rouhanifard SH, Muckenthaler MU, Tuschl T, Martin GR, Bauersachs J, Engelhardt S: MicroRNA-21 contributes to myocardial disease by stimulating MAP kinase signalling in fibroblasts. Nature 2008;456:980-984.

-22 van Rooij E, Sutherland LB, Thatcher JE, DiMaio JM, Naseem RH, Marshall WS, Hill JA, Olson EN: Dysregulation of microRNAs after myocardial infarction reveals a role of miR-29 in cardiac fibrosis. Proc Natl Acad Sci U S A 2008;105:13027-13032.

23 Duisters RF, Tijsen AJ, Schroen B, Leenders JJ, Lentink V, van der Made I, Herias V, van Leeuwen RE, Schellings MW, Barenbrug P, Maessen JG, Heymans S, Pinto YM, Creemers EE: MiR-133 and miR-30 regulate connective tissue growth factor: Implications for a role of microRNAs in myocardial matrix remodeling. Circ Res 2009;104:170-178, 6p-178p.

24 Derynck R, Zhang YE: Smad-dependent and Smad-independent pathways in TGF-beta family signalling. Nature 2003;425:577-584.

25 Zhong X, Chung AC, Chen HY, Meng XM, Lan HY: Smad3-mediated upregulation of miR-21 promotes renal fibrosis. J Am Soc Nephrol 2011;22:1668-1681.

-26 Zhao J, Tang N, Wu K, Dai W, Ye C, Shi J, Zhang J, Ning B, Zeng X, Lin Y: MiR-21 simultaneously regulates ERK1 signaling in HSC activation and hepatocyte EMT in hepatic fibrosis. Plos One 2014; 9:e108005.

-27 Liu G, Friggeri A, Yang Y, Milosevic J, Ding Q Thannickal VJ, Kaminski N, Abraham E: MiR-21 mediates fibrogenic activation of pulmonary fibroblasts and lung fibrosis. J Exp Med 2010;207:1589-1597.

28 Blom JN, Lu X, Arnold P, Feng Q: Myocardial infarction in neonatal mice, a model of cardiac regeneration. J Vis Exp 2016

29 Gamba L, Harrison M, Lien CL: Cardiac regeneration in model organisms. CURR TREAT OPTIONS Cardiovasc Med 2014;16:288.

-30 Haubner BJ, Schuetz T, Penninger JM: A reproducible protocol for neonatal ischemic injury and cardiac regeneration in neonatal mice. Basic Res Cardiol 2016;111:64.

-31 Zhao J, Lei H: Tripartite motif protein 72 regulates the proliferation and migration of rat cardiac fibroblasts via the transforming growth factor-beta signaling pathway. Cardiology 2016;134:340-346.

32 Oldfield MD, Bach LA, Forbes JM, Nikolic-Paterson D, McRobert A, Thallas V, Atkins RC, Osicka T, Jerums G, Cooper ME: Advanced glycation end products cause epithelial-myofibroblast transdifferentiation via the receptor for advanced glycation end products (RAGE). J Clin Invest 2001;108:1853-1863.

-33 Cikos S, Koppel J: Transformation of real-time PCR fluorescence data to target gene quantity. Anal Biochem 2009;384:1-10. 


\section{Cellular Physiology Cell Physiol Biochem 2017;42:2207-2219

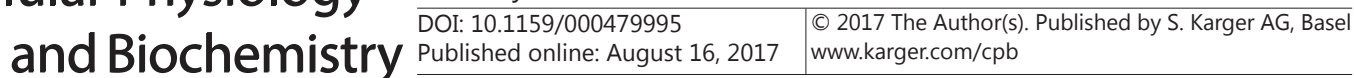 \\ Yuan et al.: MiR-21 Promotes Cardiac Fibrosis}

-34 van der Straaten HM, Canninga-van DM, Verdonck LF, Castigliego D, Borst HP, Aten J, Fijnheer R: Extradomain-A fibronectin: A new marker of fibrosis in cutaneous graft-versus-host disease. J Invest Dermatol 2004;123:1057-1062.

35 Meiners S, Hocher B, Weller A, Laule M, Stangl V, Guenther C, Godes M, Mrozikiewicz A, Baumann G, Stangl K: Downregulation of matrix metalloproteinases and collagens and suppression of cardiac fibrosis by inhibition of the proteasome. Hypertension 2004;44:471-477.

-36 Yang L, Tang J, Chen H, Ge D, Sui T, Que J, Cao X, Ge Y: Taurine Reduced Epidural Fibrosis in Rat Models after Laminectomy via Downregulating EGR1 CELL PHYSIOL BIOCHEM 2016;38:2261-2271.

-37 Biernacka A, Frangogiannis NG: Aging and cardiac fibrosis. Aging Dis 2011;2:158-173.

-38 Saito S, Matsumiya G, Sakaguchi T, Miyagawa S, Yamauchi T, Kuratani T, Sawa Y: Cardiac fibrosis and cellular hypertrophy decrease the degree of reverse remodeling and improvement in cardiac function during left ventricular assist. J Heart Lung Transplant 2010;29:672-679.

-39 Lan HY: Diverse roles of TGF-beta/Smads in renal fibrosis and inflammation. Int J Biol Sci 2011;7:10561067.

40 Samarakoon R, Overstreet JM, Higgins PJ: TGF-beta signaling in tissue fibrosis: Redox controls, target genes and therapeutic opportunities. Cell Signal 2013;25:264-268.

41 Zhang L, Liu C, Meng XM, Huang C, Xu F, Li J: Smad2 protects against TGF-beta1/Smad3-mediated collagen synthesis in human hepatic stellate cells during hepatic fibrosis. Mol Cell Biochem 2015;400:17-28.

42 Nakao A, Imamura T, Souchelnytskyi S, Kawabata M, Ishisaki A, Oeda E, Tamaki K, Hanai J, Heldin CH, Miyazono K, Ten DP: TGF-beta receptor-mediated signalling through Smad2, Smad3 and Smad4 Embo J 1997;16:5353-5362.

-43 McClelland AD, Herman-Edelstein M, Komers R, Jha JC, Winbanks CE, Hagiwara S, Gregorevic P, Kantharidis P, Cooper ME: MiR-21 promotes renal fibrosis in diabetic nephropathy by targeting PTEN and SMAD7 Clin Sci (Lond) 2015;129:1237-1249.

-44 Briones-Orta MA, Tecalco-Cruz AC, Sosa-Garrocho M, Caligaris C, Macias-Silva M: Inhibitory Smad7: Emerging roles in health and disease. Curr Mol Pharmacol 2011;4:141-153.

45 Dooley S, Hamzavi J, Breitkopf K, Wiercinska E, Said HM, Lorenzen J, Ten DP, Gressner AM: Smad7 prevents activation of hepatic stellate cells and liver fibrosis in rats. Gastroenterology 2003;125:178-191.

-46 Nakao A, Afrakhte M, Moren A, Nakayama T, Christian JL, Heuchel R, Itoh S, Kawabata M, Heldin NE, Heldin CH, Ten DP: Identification of Smad7, a TGFbeta-inducible antagonist of TGF-beta signalling. Nature 1997;389:631-635.

47 Nakerakanti S, Trojanowska M: The role of TGF-beta receptors in fibrosis. Open Rheumatol J 2012;6:156162.

48 Worthington JJ, Fenton TM, Czajkowska BI, Klementowicz JE, Travis MA: Regulation of TGFbeta in the immune system: An emerging role for integrins and dendritic cells. Immunobiology 2012;217:1259-1265.

-49 Verrecchia F, Chu ML, Mauviel A: Identification of novel TGF-beta /Smad gene targets in dermal fibroblasts using a combined cDNA microarray/promoter transactivation approach. J Biol Chem 2001;276:1705817062.

50 Chen SJ, Yuan W, Mori Y, Levenson A, Trojanowska M, Varga J: Stimulation of type I collagen transcription in human skin fibroblasts by TGF-beta: Involvement of Smad 3 J Invest Dermatol 1999;112:49-57. 